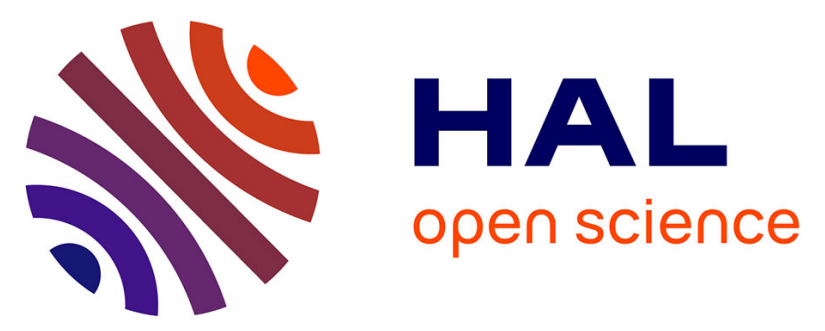

\title{
Microalgae amino acid extraction and analysis at nanomolar level using electroporation and capillary electrophoresis with laser-induced fluorescence detection
}

Reine Nehmé, Carla Atieh, Syntia Fayad, Bérengère Claude, Agnès Chartier, Mona Tannoury, Fatma Elleuch, Slim Abdelkafi, Chantal Pichon, Philippe

Morin

\section{To cite this version:}

Reine Nehmé, Carla Atieh, Syntia Fayad, Bérengère Claude, Agnès Chartier, et al.. Microalgae amino acid extraction and analysis at nanomolar level using electroporation and capillary electrophoresis with laser-induced fluorescence detection. Journal of Separation Science, 2017, 40 (2), pp.558-566. 10.1002/jssc.201601005 . hal-01618682

\section{HAL Id: hal-01618682 \\ https://hal.science/hal-01618682}

Submitted on 25 Jun 2021

HAL is a multi-disciplinary open access archive for the deposit and dissemination of scientific research documents, whether they are published or not. The documents may come from teaching and research institutions in France or abroad, or from public or private research centers.
L'archive ouverte pluridisciplinaire HAL, est destinée au dépôt et à la diffusion de documents scientifiques de niveau recherche, publiés ou non, émanant des établissements d'enseignement et de recherche français ou étrangers, des laboratoires publics ou privés. 
Microalgae amino acid extraction and analysis at nanomolar level using electroporation and capillary electrophoresis with laser-induced fluorescence detection

Reine Nehmé* ${ }^{1}$, Carla Atieh ${ }^{1}$, Syntia Fayad ${ }^{1}$, Bérengère Claude ${ }^{1}$, Agnès Chartier ${ }^{1}$, Mona Tannoury $^{2}$, Fatma Elleuch ${ }^{3,4}$, Slim Abdelkafi ${ }^{3}$, Chantal Pichon ${ }^{4}$, Philippe Morin ${ }^{1}$

${ }^{1}$ Institut de Chimie Organique et Analytique (ICOA), Université d'Orléans - CNRS FR 2708 UMR 7311, Orléans, France

${ }^{2}$ Département de Biologie, Faculté des Sciences II, Université Libanaise, Fanar, Liban

3Biotechnologie des algues, Département de Génie biologique, Ecole Nationale d'Ingénieurs de Sfax, University of Sfax, Tunisia

${ }^{4}$ Centre de Biophysique moléculaire, CNRS UPR4301 et Université d'Orléans, France

Running title: Electroporation and CE-LIF analysis

Abbreviations: a.a., amino acid; DS, Dunaliella salina; FITC, fluorescein isothiocyanate; $\boldsymbol{\alpha}$-Ala, $\alpha$-Alanine; $\boldsymbol{\beta}$-Ala, $\beta$-Alanine; D-Ile, D-allo-isoleucine; D-Arg, D-Arginine; L-Asn, LAsparagine; L-Cit, L-Citrulline; D-Gln, D-Glutamine; L-Orn, L-Ornithine.

Key words: amino acid extraction, capillary electrophoresis, electroporation, laser-induced fluorescence detection, microwave-assisted derivatization 
* Corresponding author: Dr. Reine Nehmé, ICOA, Université d’Orléans - CNRS, BP 6759, rue de Chartres, 45067 Orléans cedex 2, France.

e-mail: reine.nehme@univ-orleans.fr ; Tel: +33-2-38-49-27-75 ; Fax: +33-2-38-41-72-81

\begin{abstract}
Amino acids play a key role in food analysis, clinical diagnostics and biochemical research. Capillary electrophoresis with laser-induced fluorescence detection was used for the analysis of several amino acids. Amino acid labeling with fluorescein isothiocyanate was conducted using microwave-assisted derivatization at $80^{\circ} \mathrm{C}(680 \mathrm{~W})$ during only $150 \mathrm{~s}$. Good electrophoretic resolution was obtained using a background electrolyte composed of sodium tetraborate buffer $(100 \mathrm{mM} ; \mathrm{pH} 9.4)$ and $\beta$-cyclodextrin $(10 \mathrm{mM})$, and the limits of quantification were $3-30 \mathrm{nM}$.

The developed capillary electrophoresis with laser-induced fluorescence method was used to analyze amino acids in Dunaliella salina green algae grown under different conditions. A simple extraction technique based on electroporation of the cell membrane was introduced. A home-made apparatus allowed the application of direct and alternating voltages across the electrochemical compartment containing a suspension of microalgae in distilled water at 2.5 g. $\mathrm{L}^{-1}$. A direct voltage of $12 \mathrm{~V}$ applied for 4 min gave the optimum extraction yield. Results were comparable to those obtained with accelerated-solvent extraction. The efficiency of electroporation in destroying microalgae membranes was shown by examining the algae surface morphology using scanning electron microscopy. Stress conditions were found to induce the production of amino acids in Dunaliella salina cells.
\end{abstract}

\title{
1. Introduction
}


Amino acids are organic compounds that exhibit a major role in many fields (nutrition, health, cosmetics, biochemistry, etc). Several cosmetic products have proved to bring flexibility, softness and elasticity to human skin due to their content in amino acids. Their level in stratum corneum which is the outermost layer of the epidermis and the protecting barrier of the skin is a potential marker of this organ health. Amino acid systemic level may be used to diagnose inherited metabolic diseases. Thus, quantitative and qualitative analysis of amino acids is critical [1-3]. Detection of amino acids from different matrices at trace levels is difficult due to their physicochemical properties, such as absence of chromophores, amphotericity, non-volatile nature, high polarity, and complexation with metal ions [4]. Several analytical methods for analyzing amino acids have been reported in the literature based on chromatographic [5-11] and electrophoretic methodologies [12-18]. Different detectors can be used such as UV (UV/VIS) [5, 19, 20], fluorescence [15, 21-26], conductivity [18] and MS detection [11, 16, 27-30]. Recently, CE-MS was used for the identification of amino acids due to its capability to differentiate overlapping peaks with distinct mass-to-charge ratios $[29,30]$. CE-LIF is considered as an alternative method and a powerful analytical technique, due to its sensitivity and selectivity [15, 22-26, 31]. According to some reviews that described the advances in amino acid analysis by CE, LIF provides the best LOD among the other detection modes available for CE [14].

Since only few amino acids show strong native fluorescence, a derivatization reaction with suitable fluorogenic reagent is needed to enhance the sensitivity $[22,26]$. A wide variety of labeling agents are commonly used such as 6-carboxyfluorescein (6-FAM), 5-(4,6-dichloro-striazin-2-ylamino) fluorescein (DTAF) [32] and fluorescein isothiocyanate isomer I (FITC). FITC is widely used as a derivatization reagent for primary amine group. Its derivatives are easily formed and generate strong fluorescence signals with excitation and emission wavelengths $(488 / 520 \mathrm{~nm})$ compatible with an argon ion laser. Derivatization can be obtained 
after incubation, in the dark, at room temperature for $16 \mathrm{~h}[33,34]$ or at $50^{\circ} \mathrm{C}$ for $5 \mathrm{~h}[35,36]$. Liwei Cao et al. [4] also proposed a microwave (MW)-assisted derivatization approach to accelerate labeling reaction kinetics and hence to reduce derivatization time to $150 \mathrm{~s}$. In inorganic and organic chemistry, microwave technology has been used since the late 1970s and the mid-1980s, respectively. The main advantages of microwave assisted organic synthesis are solvent-free use, shorter reaction times and expanded reaction range which make this technique very interesting [37].

Many studies have been done on the derivatization and separation of standard amino acids, but few papers have been devoted to the separation of non-standard or non-protein amino acids by $\mathrm{CE}$ and, to our knowledge, no CE-LIF method have been developed so far to separate and detect these amino acids from microalgae. For this, the analysis of amino acids in Dunaliella salina (DS) microalgae was conducted. Indeed, chemical studies on microalgae are complicated by difficulties mainly connected with the influence of nutrients and contaminants in their environment as well as by climatic factors on the biosynthesis of natural products [38]. DS microalga is known to be the best commercial source of natural $\beta$-carotene. It can accumulate significant amounts of valuable chemicals such as carotenoids, lipids, vitamins and proteins. Additionally, it has a high potential value for biotechnological processes such as treatment of wastewater [39]. In regard to amino acid extraction from microalgae a new method based on low voltage (few V/cm, few $\mathrm{mA}$ ) was developed. Low voltage (or low current) can induce iontophoresis phenomena implicating the motion of ions across the cell membrane under the influence of the electric field. Electroporation and reverse iontophoresis have been successfully used for extraction of transdermal multi-biomarkers, like urea, prostate-specific antigen (PSA), and osteopontin [40]. Reverse iontophoresis across the skin was also shown to be a useful alternative for non-invasive drug monitoring [41]. Moreover, it was shown that electrically based disruption techniques such as pulsed electric 
field (PEF) (20 kV/cm, 1-4 ms) and high-voltage electrical discharge (HVED) (40 kV/cm, 1$4 \mathrm{~ms}$ ) allow selective extraction of water soluble ionic components and microelements, small molecular weight organic compounds and water soluble proteins in a short time [42, 43]. In fact, electroporation is an effective process to breach cell membrane barrier by applying a voltage, and has been used for the extraction of intracellular protein and small molecules from bacterial and eukaryotes cells. In an electroporation process, cells are exposed to an external electric field which induces a potential difference across the membrane. The induced transmembrane potential $\left(\Delta \psi_{E}\right)$ is given by the following equation [36]:

$$
\Delta \psi_{E}=1.5 \mathrm{~g}(\lambda) r E \cos \theta
$$

Where $g(\lambda)$ is a complex function of the membrane and buffer conductivities, $r$ is the radius of the cell, $E$ is the electric field intensity and $\theta$ is the angle between the normal to the membrane surface and the electric field direction.

When $\Delta \psi_{E}$ exceeds a threshold, the cell membrane can be irreversibly broken down. As a consequence, cell lysis and intracellular content release occur.

The aim of this study was to develop a CE-LIF method for the sensitive determination of amino acids in microalgae extracts. For this, the fluorescent labeling and the electrophoretic separation of amino acids were optimized, and a new extraction procedure based on electroporation at low voltage was introduced. Dunaliella salina (DS) microalgae were used as model algae to evaluate the efficiency of the developed approach.

\section{Materials and methods}

\subsection{Chemicals and materials}

All reagents employed were of analytical grade. D-Glutamine (purity: 98\%), D-arginine (purity: 98\%), D-allo-isoleucine (purity: 98\%), L-asparagine purity: 98\%), L-citrulline (purity: 
98\%), L-ornithine (purity: 99\%), L- $\alpha$-alanine, L- $\beta$-alanine, $\alpha$ - and $\beta$-cyclodextrin (purity: 90\%), FITC isomer I (purity: 98\%) and sodium tetraboratedecahydrate $\left(\mathrm{Na}_{2} \mathrm{~B}_{4} \mathrm{O}_{7} \cdot 10 \mathrm{H}_{2} \mathrm{O}\right.$, purity $\geq 99.5 \%$ ) were purchased from Sigma-Aldrich (Saint-Quentin-Fallavier, France). Ultra-pure water (18 M $\Omega . \mathrm{cm})$ was produced from an Elgasat apparatus (Elga, Villeurbanne, France).

\subsection{Solutions}

All solutions were prepared with ultra-pure water.

-Separation or BGE: Unless otherwise stated, borate buffer (10 mM or $100 \mathrm{mM}, \mathrm{pH} 9.4)$ was used as a separation BGE by dissolving appropriate amount of sodium tetraborate decahydrate in distilled water. $10 \mathrm{mM}$ of alpha-cyclodextrin $(\alpha-\mathrm{CD})$ or beta-cyclodextrin $(\beta-$ CD) were added to the BGE to improve peak resolution.

-Derivatization buffer (for standard amino acids): a borate buffer at $10 \mathrm{mM}$ and $\mathrm{pH} 9.4$ was used for fluorescent labeling of amino acids.

The different buffers were prepared fresh each day. Their $\mathrm{pH}$ was checked with a Meterlab PHM201 Portable pH Meter (Radiometer Analytical, Villeurbanne, France).

-Stock solutions: Amino acid and FITC stock solutions were prepared respectively at $6 \mathrm{mM}$ and at $10 \mathrm{mM}$ in the derivatization buffer and stored at $-20^{\circ} \mathrm{C}$ in the dark. These solutions were diluted appropriately each day in the same buffer.

\subsection{Dunaliella salina microalgae media and cultivation}

Dunaliella salina strain used in this work was isolated from the Sebkha of Sidi El Hani (Tunisia).

-Culture medium: the culture medium used was the F/2 [44] using artificial seawater ASW. The composition of $1 \mathrm{~L}$ of $\mathrm{F} / 2$ was as following: $996.5 \mathrm{~mL} A S W ; 1 \mathrm{~mL} \mathrm{NaNO}$ (75 g.L-1); 1

$\mathrm{mL} \mathrm{NaH}{ }_{2} \mathrm{PO}_{4}\left(5\right.$ g. $\left.\mathrm{L}^{-1}\right) ; 1 \mathrm{~mL}$ trace metals $(100 \mathrm{~mL}): \mathrm{CuSO}_{4} .5 \mathrm{H}_{2} \mathrm{O} 0.98 \mathrm{~g}, \mathrm{ZnSO}_{4} .7 \mathrm{H}_{2} \mathrm{O} 2.2$ g, $\mathrm{CoCl}_{2} .6 \mathrm{H}_{2} \mathrm{O} 1 \mathrm{~g}, \mathrm{MnCl}_{2} .4 \mathrm{H}_{2} \mathrm{O} 18 \mathrm{~g}, \mathrm{Na}_{2} \mathrm{MoO}_{4} .2 \mathrm{H}_{2} \mathrm{O} 0.63 \mathrm{~g}$ ); $0.5 \mathrm{~mL}$ vitamin solution (1 
L: Biotin $1 \mathrm{mg}, 1 \mathrm{mg} \mathrm{B}_{12}$ and $20 \mathrm{mg}$ Thiamin $\mathrm{HCl}$ ). Where ASW composition was as following (1 L): $\mathrm{NaCl} 27 \mathrm{~g} ; \mathrm{MgSO}_{4} 6.6 \mathrm{~g} ; \mathrm{MgCl}_{2} 25.6 \mathrm{~g} ; \mathrm{CaCl}_{2} 1.5 \mathrm{~g} ; \mathrm{KNO}_{3} 1 \mathrm{~g} ; \mathrm{KH}_{2} \mathrm{PO}_{4}$ $0.07 \mathrm{~g} ; \mathrm{NaHCO}_{3} 0.04 \mathrm{~g} ; 20 \mathrm{~mL}$ Tris buffer $(\mathrm{pH}$ 7.6) $1 \mathrm{M}$.

-Cultivation conditions: for normal cultures, nitrogen was at $1.07 \mathrm{~g} . \mathrm{L}^{-1}$ whereas for stressed cultures, the nitrogen was limited at 0.03 g. $\mathrm{L}^{-1}$.

Microalgae were harvested using centrifugation under $5000 \mathrm{rpm}$ for $10 \mathrm{~min}$ (Jouan BR4I multifunction, Thermo, Illkirch, France) and then the microalgae cells were freeze-dried (lyophilized).

\subsection{Instrumentation and operating conditions}

All experiments were performed with a CE instrument: AB Sciex PA 800+ equipped with a LIF detector (Brea, CA, USA). The excitation was carried out with an Argon ion laser at a wavelength of $488 \mathrm{~nm}$. The band-pass filter $520 \mathrm{~nm}$ was used for emission. Data acquisition and instrument control were carried out using 32 Karat acquisition system software. Separations were carried out using fused-silica capillaries of $60 \mathrm{~cm}$ total length $(50 \mathrm{~cm}$ detection length) purchased from Polymicro Technologies (Phoenix, AZ, USA). The inner diameter was 50 or $75 \mu \mathrm{m}$. The capillary was maintained at $25^{\circ} \mathrm{C}$ and separation was conducted at $+25 \mathrm{kV}$. Hydrodynamic injection mode with 0.5 psi pressure was applied for 5 S.

Each new capillary was conditioned by flushing it with $1 \mathrm{M} \mathrm{NaOH}(10 \mathrm{~min})$, water (5 min) and BGE (15 min). Between two runs, the capillary was flushed with $\mathrm{NaOH} 1 \mathrm{M}(1 \mathrm{~min})$, water $(1 \mathrm{~min})$ and BGE $(3 \mathrm{~min})$. All rinse cycles were conducted at 20 psi pressure. The buffer vials were renewed every three analyses.

\subsection{Derivatization procedure}

Pre-capillary derivatization of analytes was applied because labeling reaction is slow and thus inadequate for in-capillary derivatization mode. 
Different ratios of FITC and amino acids were tested to evaluate the efficiency of the derivatization. In a $1 \mathrm{~mL}$ total volume, the final amino acid concentration was $1 \mu \mathrm{M}$ with concentration ratios of FITC to each amino acid of $2: 1,1: 1,1: 5$ or $1: 20$. The mixture vials were capped, homogenized and allowed to stand in the dark at $25^{\circ} \mathrm{C}$ for $5 \mathrm{~h}$ or $50^{\circ} \mathrm{C}$ for $16 \mathrm{~h}$. After derivatization, the vials were kept at $-20^{\circ} \mathrm{C}$. Before $\mathrm{CE}$ analysis, the labeling mixture was diluted with the derivatization borate buffer $(10 \mathrm{mM}, \mathrm{pH} 9.5)$.

The same procedure was conducted for microwave-assisted derivatization using a microwave synthesis labstation (Start Synth, Milestone, Bergamo). Heating was conducted with microwave irradiation under $680 \mathrm{~W}$ at constant temperature of $80^{\circ} \mathrm{C}$ for only $150 \mathrm{~s}$.

Blank assays were conducted to evaluate the stability of FITC in the derivatization conditions. For this, FITC was prepared in the derivatization borate buffer and heated at $80^{\circ} \mathrm{C}$ for 150 s by MW or by conventional heating.

\subsection{Amino acid extraction from Dunaliella salina microalgae}

-Electrochemical / electroporation extraction: a homemade device was used for amino acid extraction studies. It consisted of two parallel platinum electrode wires, each one having a surface area of $0.6 \mathrm{~cm}^{2}(1 \mathrm{~cm}$ length $\times 0.1 \mathrm{~cm}$ radius $)$, connected to the positive and negative outlets of a DC (AL841B 30VA - ELC, Annecy, France) or an AC power supply (Evolution F6F12 100VA - Jeulin, Evreux, France). The inter-electrode gap was $1 \mathrm{~cm}$. Two samples of Dunaliella salina (DS) cultivated under different conditions (normal and stressed by adding $\mathrm{NaCl}$ to medium culture) were analyzed. $50 \mathrm{mg}$ of DS were suspended in $20 \mathrm{~mL}$ of distilled water $\left(2.5\right.$ g. $\left.\mathrm{L}^{-1}\right)$ and placed in glass vessel on a magnetic stirrer. The sample was stirred constantly to prevent cells from settling out of suspension over the time-course of extraction and to maintain steady the diffusion around the electrodes. Extraction was performed by applying voltage $(6,12$ or $36 \mathrm{~V})$ to the suspension for certain duration. After each extraction, $1 \mathrm{~mL}$ of the suspension ( $\mathrm{pH} \sim 8.4$ ) was collected, centrifuged and the supernatant was stored 
when not in use at $-20^{\circ} \mathrm{C}$. Before CE-LIF analysis, FITC was added to the suspension for amino acid derivatization as previously described. Extraction conditions were optimized by quantifying the extracted amino acids by CE-LIF. In optimal extraction conditions, the electrochemical extraction was repeated twice $(n=2)$.

The effect of the electric field on the Dunaliella salina (DS) cells was evaluated using a scanning electron microscope (Hitachi S-45000, Hitachi High-Technologies Europe GmbH, Japan). Samples were lyophilized and carbon-coated before SEM-FEG (field emission gun) images (obtained at $2 \mathrm{kV}$ voltage).

-Accelerated solvent extraction (ASE): a Dionex accelerated solvent extractor ASE-150 (Thermo Fisher Scientific, Courtaboeuf, France) was used. The lyophilized powder of microalgae $(50 \mathrm{mg})$ was extracted in $5 \mathrm{~mL}$ stainless-steel vessel with water $(15 \mathrm{~mL})$ as solvent using three static cycles for $10 \mathrm{~min}$ each, a flush volume of $70 \%$ and a purge with nitrogen gas of $100 \mathrm{~s}$ at the end of each extraction. Extractions were carried out at $130^{\circ} \mathrm{C}$ and under a pressure of 110 bars. Water solvent was evaporated under vacuum using a rotary evaporator (Buchi Labortechnik AG, Switzerland) to obtain a dried crude extract. Extraction was repeated twice $(n=2)$. The residue was recovered in $1 \mathrm{~mL}$ of derivatization buffer for labeling before CE-LIF analysis. It was stored when not in use at $-20^{\circ} \mathrm{C}$.

\section{Results and discussion}

CE-LIF was chosen for the analysis of amino acids extracted by electroporation from Dunaliella salina microalgae. The fluorescent labeling of amino acids by fluorescein isothiocyanante as well as electrophoretic separation conditions were optimized to obtain short labeling time and high sensitivity of the CE-LIF method.

\subsection{Labeling of amino acids with fluorescein isothiocyanate isomer I}


All amino acids (Asn, Gln, Arg, Glu, Orn, Ile, Cit and Ala) selected possess a primary amino group, which may react with the isothiocyanate group of FITC to form the fluorescent derivatives. Labeling with FITC is commonly carried out in borate buffer to minimize the hydrolysis of the labeling agent and consequently the number of undesired fluorescent byproducts $[45,46]$. Moreover, the derivatization reaction must be performed under alkaline conditions [47] to favor the nucleophilic addition of the neutral deprotonated amino group to the double bound of the FITC. Therefore, $10 \mathrm{mM}$ sodium tetraborate at $\mathrm{pH} 9.4$ was used as derivatization buffer for developing the amino acid CE-LIF analysis method.

Different conditions were tested to optimize the yield of the labeling reaction, which was evaluated by $\mathrm{CE}$ using corrected peak-areas of each derivative. The parameters studied were the ratio of FITC and amino acids, and the reaction time and temperature. The concentration of FITC was optimized while keeping amino acid concentration constant $(1 \mu \mathrm{M})$. The tested ratios of FITC to amino acids were $2: 1,1: 1,1: 5$ and 1:20. The obtained mixture was homogenized and allowed to react in the dark at room temperature $\left(25^{\circ} \mathrm{C}\right)$ for $5 \mathrm{~h}$ or at $50^{\circ} \mathrm{C}$ for $16 \mathrm{~h}$. The use of low concentration of FITC resulted in poor sensitivity. The increase in the concentration of FITC induced an increase in signal magnitude of amino acid and also of additional interfering signals. Blank assays (section 2.5) confirmed that these additional peaks are mainly due to impurities found in the FITC standard used (purity 98\%). The electrophoretic profiles obtained for the blank assay before and after heating were almost identical. Conventional heating had thus little influence on FITC stability. Therefore, the FITC/analyte ratio of 1:20 was chosen all along the study as a compromise between detection sensitivity and interference from FITC.

The efficiency of the derivatization reaction depends on both time and temperature. For this, the labeling reaction was successively conducted at 25,37 and $50^{\circ} \mathrm{C}$ (Figure 1) using convective heating. The highest derivative concentrations were achieved in $5 \mathrm{~h}$ at $50^{\circ} \mathrm{C}$ 
whereas $16 \mathrm{~h}$ were needed to obtain similar results at $37^{\circ} \mathrm{C}$. Further experiments were conducted to reduce the derivatization time. Performing microwave-assisted derivatization allowed the acceleration of the labeling reaction that was completed within only $150 \mathrm{~s}$ at 680 $\mathrm{W}$ and $80^{\circ} \mathrm{C}$ (Figure 1). Comparable results in terms of sensitivity were obtained by conventional convective heating but with longer reaction times (120 times). These results are consistent with literature, demonstrating that microwaves can be very efficient for remarkably accelerating fluorescent tagging[37, 48]. As for conventional convective heating, blank assays conducted (section 2.5) confirmed that MW heating had low effect on FITC stability. For the remaining of this study, microwave-assisted derivatization of amino acids with FITC in alkaline borate buffer was used for CE-LIF analysis.

\subsection{Analysis of labeled amino acids by CE with LIF detection}

Borate buffer was used as the BGE because it provides a stable EOF as reported by several authors[4]. As shown in Figure 2.a, a good separation was obtained for a standard mixture containing $1 \mu \mathrm{M}$ of D-Gln, D-Arg, L-Orn, L-Cit, $\beta$-Ala and L-Asn using $10 \mathrm{mM}$ borate buffer ( $\mathrm{pH}$ 9.4) as BGE. Peaks for all analytes were baseline resolved in less than $10 \mathrm{~min}$. L$\alpha$-Alanine and L- $\beta$-alanine could not be separated in these conditions. Several attempts were made to achieve full separation by varying $\mathrm{pH}$ value $(8.0,8.6,9.0,9.4,10.0,10.5$ and 11.0) but no significant improvement was obtained. Native $\alpha$ - and $\beta$-cyclodextrins (CD) were added to the BGE. The $\alpha-\mathrm{CD}$ did not improve resolution whereas $\beta$-CD improved Ala isomers resolution. For this, $\beta$-CD concentration $(2.5,5,7.5,10$ and $15 \mathrm{mM})$ as well as the borate buffer concentration $(10,20,30,50,75$ and $100 \mathrm{mM})$ were optimized. Best results were obtained using the following BGE: $100 \mathrm{mM}$ sodium tetraborate and $10 \mathrm{mM} \beta$ cyclodextrin at $\mathrm{pH} 9.4$. Excess current of $240 \mu \mathrm{A}$ was observed with $75 \mu \mathrm{m}$ internal diameter capillary engendering high Joule heating whereas acceptable current of $140 \mu \mathrm{A}$ was obtained with a $50 \mu \mathrm{m}$ capillary. Figure $2 . \mathrm{b}$ shows an electropherogram obtained in these conditions 
for the analysis of D-Ile, D-Gln, L-Asn, $\beta$-Ala and $\alpha$-Ala. Additional peaks observed on electropherograms are due to FITC impurities and not to the heating technique that had trivial influence on compounds stability. The developed CE-LIF method was validated in terms of linearity. Calibration linear curves were obtained for the different studied amino acids with $\mathrm{r}^{2}$ higher than 0.9975. Excellent sensitivity was found with a LOQ of a few nM for the different amino acids (3-9 nM). LOQs were obtained by injecting and analyzing each labeled amino acid at the estimated value for $\mathrm{S} / \mathrm{N}=10$. This so-called instrumental $\mathrm{LOQ}$ is different from the limit of derivatization which expresses the minimum amount of the analyte that can react with the fluorescent reagent. Repeatability was also satisfactory with RSD on migration times and on peak areas inferior to 1.2 and $1.9 \%(n=6)$, respectively.

\subsection{Analysis of amino acids in microalgae after electroporation extraction}

The previously developed CE-LIF method was applied to the analysis of amino acids in Dunaliella salina microalgae. These microalgae are well-known source of carotenoids ( $\beta$ carotene), lipids, vitamins and proteins. Electrical treatment of algae has been recently shown by Daghrir et al. [49] to be very efficient in damaging cell membranes helping lipid extraction from microalgae. Extraction efficiency is a function of the applied voltage intensity and the time when the voltage is applied. Different direct voltages were applied (6, 12 and $36 \mathrm{~V}$ ) for different durations (Table 1). At low voltage $6 \mathrm{~V} \mathrm{DC}$, no extraction was obtained due certainly to the incapacity of this electric field to damage the microalgae membrane. For higher direct voltages (12 and $36 \mathrm{~V})$, extraction was successful and three amino acids (D-Arg, L- $\alpha$-Ala and L- $\beta$-Ala) were detected and identified by CE-LIF. To further understand this process, different extraction times were studied. The Figure 3 summarizes extraction results obtained by electroporation of amino acids from Dunaliella salina green algae. As it can be seen, the best extraction results were obtained at $12 \mathrm{~V} \mathrm{DC}$ for $4 \mathrm{~min}$. When this voltage was applied for a longer time (10 $\mathrm{min})$, the amount of extracted 
amino acids decreases $(-20 \%)$ due certainly to their degradation by electrochemical reactions in contact with the electrode surface. Figure 4 shows the electropherograms for the analysis of Dunaliella salina extracts obtained by applying $12 \mathrm{~V} \mathrm{DC}$ voltage for different times. Several amino acids have been identified such as D-Arg, L- $\alpha$-Ala and L- $\beta$-Ala. Identification was done by migration time matching and by spiking the samples with labeled amino acids. On the other hand, good extraction was also obtained when applying pulses of higher voltage i.e.36 V DC during only $20 \mathrm{~s}$.

To conclude, best extraction was obtained at lower and long-lasting voltage (12 V DC x 4 min). More precisely, extraction is probably due to iontophoresis phenomenon implicating the motion of ions across the cell membrane under the influence of an electric field. For analytes such as amino acids, both electromigration as well as electroosmosis contribute to the iontophoretic extraction across the damaged membrane, resulting in increased analyte extraction. In other terms, extraction is mainly due to electroporation (increasing cell permeability) as well as to amino acid migration from the cell into the surrounding solvent.

Finally, an alternative voltage $(12 \mathrm{~V} \mathrm{AC}, 50 \mathrm{~Hz})$ has been tested applied for 4 or $10 \mathrm{~min}$ to perform the extraction by electroporation but did not engender any extraction as confirmed by CE-LIF. Indeed, when using alternative voltage, the iontophoretic extraction was reduced. Only reversible pores which reclosed rapidly may be obtained in these conditions.

In the optimum conditions (DC $12 \mathrm{~V} \mathrm{x} 4 \mathrm{~min}$ ), the reproducibility of the extraction method was excellent with RSD inferior to $3.9 \%$ on peak areas $(n=3)$. SEM-FEG images of the Dunaliella salina microalgae cells before and after electrical treatment show the change in cell morphology and illuminate the morphological impacts on disrupted cells. After application of the electrical field, the shapes of the cells became less defined confirming electroporation. 
To confirm the obtained results, the conventional extraction method ASE was conducted using the same conditions as for the electroporation extraction (50 mg of Dunaliella salina extracted with $20 \mathrm{~mL}$ of water). D-Arg and L-Ala were extracted using both methods, but approximately eight times lesser using ASE than electroporation; 0.1 versus $0.8 \mu \mathrm{M}$ for DArg and 1.0 versus $9.2 \mu \mathrm{M}$ for L-Ala. These results prove the efficiency of the developed extraction method based on electroporation. Moreover, it is worthy to note that the sensitivity of the CE-LIF method was essential to directly detect amino acids in the extracts at low range of nanomolar with no need of any pre-concentration step.

The herein developed electroporation-CE-LIF method was then used to study the effect of the cultivation conditions on the amino acid quantity in microalgae (Figure 5). Indeed, the environmental constrains increase the productivity of biologically active molecules by microalgae [38]. The same amino acids were found in the two cultivations. However, our results showed that the imposed stress conditions induced the production of a higher quantity of amino acids in Dunaliella salina than in normal conditions. For both D-Arg and L-Ala, the concentration is ten times higher in the stressed algal cultivation. Indeed, it has been shown that alanine accumulation in plants and animals in response to exposure to a variety of stress conditions is a general phenomenon. Alanine is a universal first stress signal expressed by cells $[50,51]$.

\section{Concluding remarks}

A new CE-LIF method was developed for the determination and the identification of nonstandard and standard amino acids. Microwave-assisted derivatization $\left(680 \mathrm{~W}, 80^{\circ} \mathrm{C}\right)$ was used to minimize the fluorescent labeling time to $150 \mathrm{~s}$. This analytical process has been successfully applied for the determination of amino acids in microalgae extracts. A novel extraction technique for amino acid based on electroporation of cell membrane has been 
introduced. Best extraction is obtained either after a long exposure of the vegetal cells to a low voltage (12 V DC, $4 \mathrm{~min}$ ) or a short exposure to a higher voltage (36 V DC, $20 \mathrm{~s}$ ), both of which gives good extraction yields for amino acids. The developed electroporation-CE/LIF method was used to study the influence of the cultivation conditions on amino acid expression in microalgae. Our results showed that stress conditions induced the production of amino acids in Dunaliella salina confirming that alanine is a universal first stress signal expressed by cells.

In this study, we present a proof-of-concept demonstration of a green approach to extract and analyze amino acids in microalgae. Further optimization will be necessary to identify more than two amino acids in microalgae and to expand this approach for studying varied molecular families in other algae. Several algae products have attracted great interest due to their potential practical application as pharmaceutical agents, cosmetic ingredients, energy sources, valuable food constituents, and future materials for nanotechnology.

\section{Acknowledgements}

Authors particularly acknowledge Dr Régis Delatouche (ICOA) for his essential contribution in the use of the microwave apparatus as well as Ms Salimata Diarrassouba for conducting accelerated solvent extractions. The authors would especially like to thank Mr Loïc Burnel from the Institut Universitaire Technique (IUT) of the University of Orléans for his help in the comprehension of the functioning of the electroporation process. The authors would also like to thank Mrs Annie Richard from the Centre de Microscopie Electronique of the Université of Orléans for her useful help in the SEM observations.

The authors declare that there are no conflicts of interest.

\section{References}


[1] Wang Q., Holst J., L-type amino acid transport and cancer: targeting the mTORC1 pathway to inhibit neoplasia, Am. J. Cancer Res. 2015, 5, 1281-1294.

[2] Furuse M., Screening of central functions of amino acids and their metabolites for sedative and hypnotic effects using chick models, Eur. J. Pharmacol. 2015, 762, 382-393.

[3] Lorenzo M. P., Villaseñor A., Ramamoorthy A., Garcia A., Optimization and validation of a capillary electrophoresis laser-induced fluorescence method for amino acids determination in human plasma: Application to bipolar disorder study, Electrophoresis 2013, $34,1701-1709$.

[4] Cao L., Deng T., Liang S., Tan X., Meng J., Determination of herbicides and its metabolite in soil and water samples by capillary electrophoresis-laser induced fluorescence detection using microwave-assisted derivatization, Anal. Sci. 2014, 30, 759-766.

[5] Sethuraman R., Krishnamoorthy M. G., Lee T.-L., Liu E. H. C., Chiang S., Nishimura W., Sakai M., Minami T., Tachibana S., Simultaneous analysis of D- and L-Serine in cerebrospinal fluid by use of HPLC, Clin. Chem. 2007, 53, 1489-1494.

[6] D’Orazio G., Cifuentes A., Fanali S., Chiral nano-liquid chromatography-mass spectrometry applied to amino acids analysis for orange juice profiling, Food Chem. 2008, $108,1114-1121$.

[7] Sun Y., Xu X., Mou Z., Wang J., Tan Z., Wu S., Analysis of free amino acids in Amur sturgeon by ultra-performance liquid chromatography using pre-column derivatization with 6-aminoquinolyl-carbamyl, J. Sep. Sci. 2012, 35, 3421-3426.

[8] Botero-Coy A. M., Ibáñez M., Sancho J. V., Hernández F., Improvements in the analytical methodology for the residue determination of the herbicide glyphosate in soils by liquid chromatography coupled to mass, J. Chromatogr. A 2013, 1292, 132-141. 
[9] Al-Othman Z. A., Al-Warthan A., Ali I., Advances in enantiomeric resolution on monolithic chiral stationary phases in liquid chromatography and electrochromatography, J. Sep. Sci. 2014, 37, 1033-1057.

[10] Pataj Z., Ilisz I., Gecse Z., Szakonyi Z., Fülöp F., Lindner W., Péter A., Effect of mobile phase composition on the liquid chromatographic enantioseparation of bulky monoterpenebased $\beta$-amino acids by applying chiral stationary phases based on Cinchona alkaloid, J. Sep. Sci. 2014, 37, 1075-1082.

[11] Moldoveanu S. C., Zhu J., Qian N., Free amino acids analysis by liquid chromatography with tandem mass spectrometry in several botanicals with antioxidant character, J. Sep. Sci. $2015,38,2208-2222$.

[12] Latorre R. M., Saurina J., Hernández-Cassou S., Capillary electrophoresis method for the determination of amino acids in pharmaceutical samples based on precolumn derivatization using 1,2-naphthoquinone-4-sulfonate, J. Chromatogr. Sci. 1999, 37, 353-359. [13] Molina M., Silva M., Simultaneous determination of phosphorus-containing amino acidherbicides by nonionic surfactant micellar electrokinetic chromatography with laser-induced fluorescence detection, Electrophoresis 2001, 22, 1175-1181.

[14] Liu X., Hu Y.-Q., Ma L., Lu Y.-T., Determination of phosphoamino acids derivatized with 5-(4,6-dichloro-s-triazin-2-ylamino)fluorescein by micellar electrokinetic chromatography, J. Chromatogr. A 2004, 1049, 237-242.

[15] Cao L., Zhang H., Hong W., Analysis of amino acid neurotransmitters by capillary electrophoresis and laser-induced fluorescence using a new fluorescein-derived label, Microchimica Acta 2007, 158, 361-368.

[16] Atherton T., Croxton R., Baron M., Gonzalez-Rodriguez J., Gámiz-Gracia L., GarcíaCampaña A. M., Analysis of amino acids in latent fingerprint residue by capillary electrophoresis-mass spectrometry, J. Sep. Sci. 2012, 35, 2994-2999. 
[17] Quirino J. P., Kato M., Separation of cationic analytes by nonionic micellar electrokinetic chromatography using polyoxyethylene lauryl ether surfactants with different polyoxyethylene length, J. Sep. Sci. 2014, 37, 2613-2617.

[18] Campos C. D. M., deCampos Braga P. A., Reyes F. G. R., daSilva J. A. F., Elimination of the artefact peaks in capillary electrophoresis determination of glutamate by using organic solvents in sample preparation, J. Sep. Sci. 2015, 38, 3781-3787.

[19] Nehmé R., Perrin C., Guerlavais V., Fehrentz J.-A., Cottet H., Martinez J., Fabre H., Use of coated capillaries for the electrophoretic separation of stereoisomers of a growth hormone secretagogue, Electrophoresis 2009, 30, 3772-3779.

[20] Forteschi M., Sotgia S., Assaretti S., Arru D., Cambedda D., Sotgiu E., Zinellu A., Carru C., Simultaneous determination of aromatic amino acids in human blood plasma by capillary electrophoresis with UV-absorption detection, J. Sep. Sci. 2015, 38, 1794-1799.

[21] Gassmann E., Kuo J. E., Zare R. N., Electrokinetic separation of chiral compounds, Science $1985,230,813-814$.

[22] Nickerson B., Jorgenson J. W., High sensitivity laser induced fluorescence detection in capillary zone electrophoresis, J. High. Resolut. Chromatogr. 1988, 11, 878-881.

[23] Vandenabeele-Trambouze O., Albert M., Bayle C., Couderc F., Commeyras A., Despois D., Dobrijevic M., Loustalot M.-F. G., Chiral determination of amino acids by capillary electrophoresis and laser-induced fluorescence at picomolar concentrations, J. Chromatogr. A $2000,894,259-266$.

[24] Jaworska M., Stańczyk M., Wilk M., Kłaczkow G., Anuszewska E., Barzał J., Rzepecki P., New approach for amino acid profiling in human plasma by selective fluorescence derivatization, Amino acids 2012, 43, 1653-1661. 
[25] Fayad S., Nehmé R., Lafite P., Morin P., Assaying Human Neutrophil Elastase activity by capillary zone electrophoresis combined with laser-induced fluorescence (CZE-LIF), J. Chromatogr. A 2015, 1419, 116-124.

[26] Wuethrich A., Quirino J. P., Derivatisation for separation and detection in capillary electrophoresis (2012-2015), Electrophoresis 2016, 37, 45-55.

[27] Yang W.-C., Mirzaei H., Liu X., Regnier F. E., Enhancement of amino acid detection and quantification by electrospray ionization mass spectrometry, Anal. Chem. 2006, 78, $4702-4708$.

[28] Gogichaeva N. V., Williams T., Alterman M. A., MALDI TOF/TOF Tandem mass spectrometry as a new tool for amino acid analysis, J. Am. Soc. Mass. Spectrom. 2007, 18, 279-284.

[29] Desiderio C., Iavarone F., Rossetti D. V., Messana I., Castagnola M., Capillary electrophoresis-mass spectrometry for the analysis of amino acids, J. Sep. Sci. 2010, 33, $2385-2393$.

[30] Wakayama M., Aoki N., Sasaki H., Ohsugi R., Simultaneous analysis of amino acids and carboxylic acids by capillary electrophoresis-mass spectrometry using an acidic electrolyte and uncoated fused-silica capillary, Anal. Chem. 2010, 82, 9967-9976.

[31] Couderc F., Ong-Meang V., Poinsot V., Capillary electrophoresis hyphenated with UVnative-laser induced fluorescence detection (CE/UV-native-LIF), Electrophoresis 2016, n/a.

[32] Lalljie S. P. D., Sandra P., Practical and quantitative aspects in the analysis of FITC and DTAF amino acid derivatives by capillary electrophoresis and LIF detection, Chromatographia 1995, 40, 519-526.

[33] Zhang D., Zhang J., Ma W., Chen D., Han H., Shu H., Liu G., Analysis of trace amino acid neurotransmitters in hypothalamus of rats after exhausting exercise using microdialysis, J. Chromatogr. B 2001, 758, 277-282. 
[34] Arlt K., Brandt S., Kehr J., Amino acid analysis in five pooled single plant cell samples using capillary electrophoresis coupled to laser-induced fluorescence detection, J. Chromatogr. A 2001, 926, 319-325.

[35] Zhang L., Chen H., Hu S., Shao M., Determination of the amino acid neurotransmitters in the dorsal root ganglion of the rat by capillary electrophoresis with a laser-induced fluorescence-charge coupled device, J. Chromatogr. B 1998, 707, 59-67.

[36] Weaver J. C., Chizmadzhev Y. A., Theory of electroporation: A review, Bioelectrochem. Bioenerg. 1996, 41, 135-160.

[37] Lidström P., Tierney J., Wathey B., Westman J., Microwave assisted organic synthesis a review, Tetrahedron 2001, 57, 9225-9283.

[38] Mimouni V., Ulmann L., Pasquet V., Mathieu M., Picot L., Bougaran G., Cadoret J. P., Morant-Manceau A., Schoefs B., The potential of microalgae for the production of bioactive molecules of pharmaceutical interest, Curr. Pharm. Biotechnol. 2012, 13, 2733-2750.

[39] Hosseini T. A., Shariati M., Dunaliella biotechnology: methods and applications, J. Appl. Microbiol. 2009, 107, 14-35.

[40] Ching C. T.-S., Fu L.-S., Sun T.-P., Hsu T.-H., Chang K.-M., Use of electroporation and reverse iontophoresis for extraction of transdermal multibiomarkers, Int. J. Nanomedicine $2012,7,885-894$.

[41] Sieg A., Jeanneret F., Fathi M., Hochstrasser D., Rudaz S., Veuthey J.-L., Guy R. H., Begoña Delgado-Charro M., Extraction of amino acids by reverse iontophoresis in vivo, Eur. J. Pharm. Biopharm. 2009, 72, 226-231.

[42] Grimi N., Dubois A., Marchal L., Jubeau S., Lebovka N. I., Vorobiev E., Selective extraction from microalgae Nannochloropsis sp. using different methods of cell disruption, Bioresource Technol. 2014, 153, 254-259. 
[43] Nehmé H., Nehmé R., Lafite P., Duverger E., Routier S., Morin P., Electrophoretically mediated microanalysis for in-capillary electrical cell lysis and fast enzyme quantification by capillary electrophoresis, Anal. Bioanal. Chem. 2013, 405, 9159-9167.

[44] Guillard R. R. L., in: Smith, W. L., Chanley, M. H. (Eds.), Culture of Marine Invertebrate Animals, Plenum Press, New York, USA 1975, pp. 29-60.

[45] Poboży E., Czarkowska W., Trojanowicz M., Determination of amino acids in saliva using capillary electrophoresis with fluorimetric detection, J. Biochem. Bioph. Methods $2006,67,37-47$.

[46] Korchane S., Pallandre A., Przybylski C., Poüs C., Gonnet F., Taverna M., Daniel R., Le Potier I., Derivatization strategies for CE-LIF analysis of biomarkers: Toward a clinical diagnostic of familial transthyretin amyloidosis, Electrophoresis 2014, 35, 1050-1059.

[47] Bernardo S. D., Weigele M., Toome V., Manhart K., Leimgruber W., Böhlen P., Stein S., Udenfriend S., Studies on the reaction of fluorescamine with primary amines, Arch. Biochem. Biophys. 1974, 163, 390-399.

[48] Chen K.-F., Lee H., Liu J.-T., Lee H.-A., Lin C.-H., A microwave-assisted fluorescent labeling method for the separation and detection of amphetamine-like designer drugs by capillary electrophoresis, Forensic Sci. Int., 228, 95-99.

[49] Daghrir R., Igounet L., Brar S.-K., Drogui P., Novel electrochemical method for the recovery of lipids from microalgae for biodiesel production, J. Taiwan Inst. Chem. E. 2014, $45,153-162$.

[50] Ben-Izhak M. E., Parola A. H., Kost D., Low-frequency electromagnetic fields induce a stress effect upon higher plants, as evident by the universal stress signal, alanine, Biochem. Biophys. Res. Commun. 2003, 302, 427-434. 
[51] Ben-Izhak M. E., Levkovitz A., Kost D., Ultraviolet radiation induces stress in etiolated Landoltia punctata, as evidenced by the presence of alanine, a universal stress signal: a $15 \mathrm{~N}$ NMR study, Plant Biol. 2015, 17, 101-107.

List of figures

Figure 1. Effect of heating procedure and time upon derivatization yield of amino acids by FITC

The derivatization yield $100 \%$ corresponds to the maximum peak area obtained using microwave-assisted derivatization.

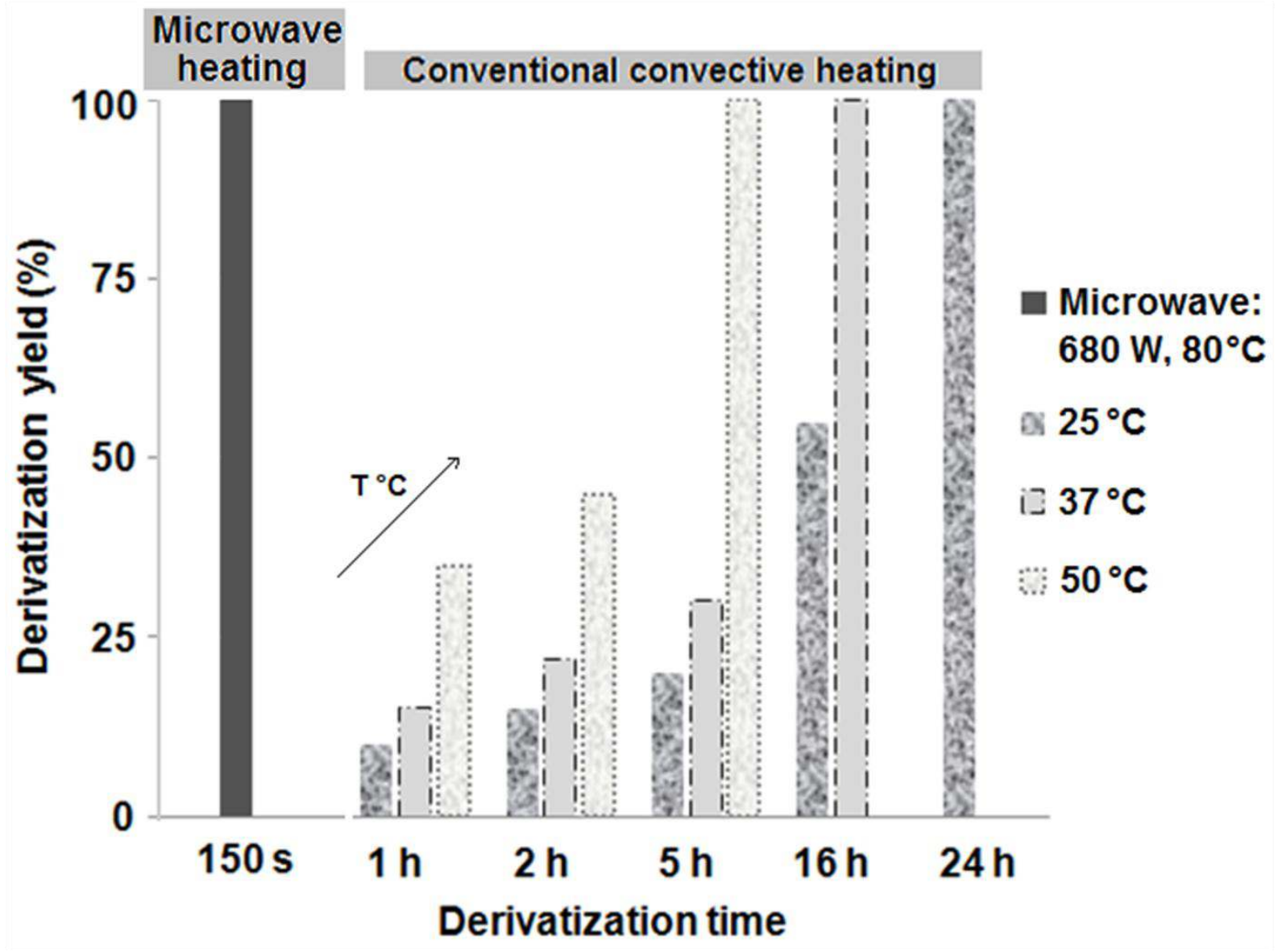


Figure 2. Separation of standard mixtures of amino acids labeled with FITC by CE-LIF.

Separation voltage: $+25 \mathrm{kV}$; hydrodynamic injection: 0.5 psi for $5 \mathrm{~s}$; excitation and emission wavelengths: 488/520 nm; amino acid concentration: $100 \mathrm{nM}$. [FITC]/[a.a.] = 1:20

(a) BGE: $10 \mathrm{mM}$ sodium tetraborate buffer (pH 9.4); capillary: $60 \mathrm{~cm}$ x $50 \mathrm{~cm}$ x $75 \mu \mathrm{m}$ I.D.; derivatization: $50^{\circ} \mathrm{C} \times 5 \mathrm{~h}$.

(b) BGE: $100 \mathrm{mM}$ sodium tetraborate buffer $+10 \mathrm{mM} \beta-\mathrm{CD}(\mathrm{pH} 9.4)$; capillary: $60 \mathrm{~cm} \mathrm{x}$ $50 \mathrm{~cm}$ x $50 \mu \mathrm{m}$ I.D.; microwave assisted derivatization: $150 \mathrm{~s}$ x $680 \mathrm{~W}$.
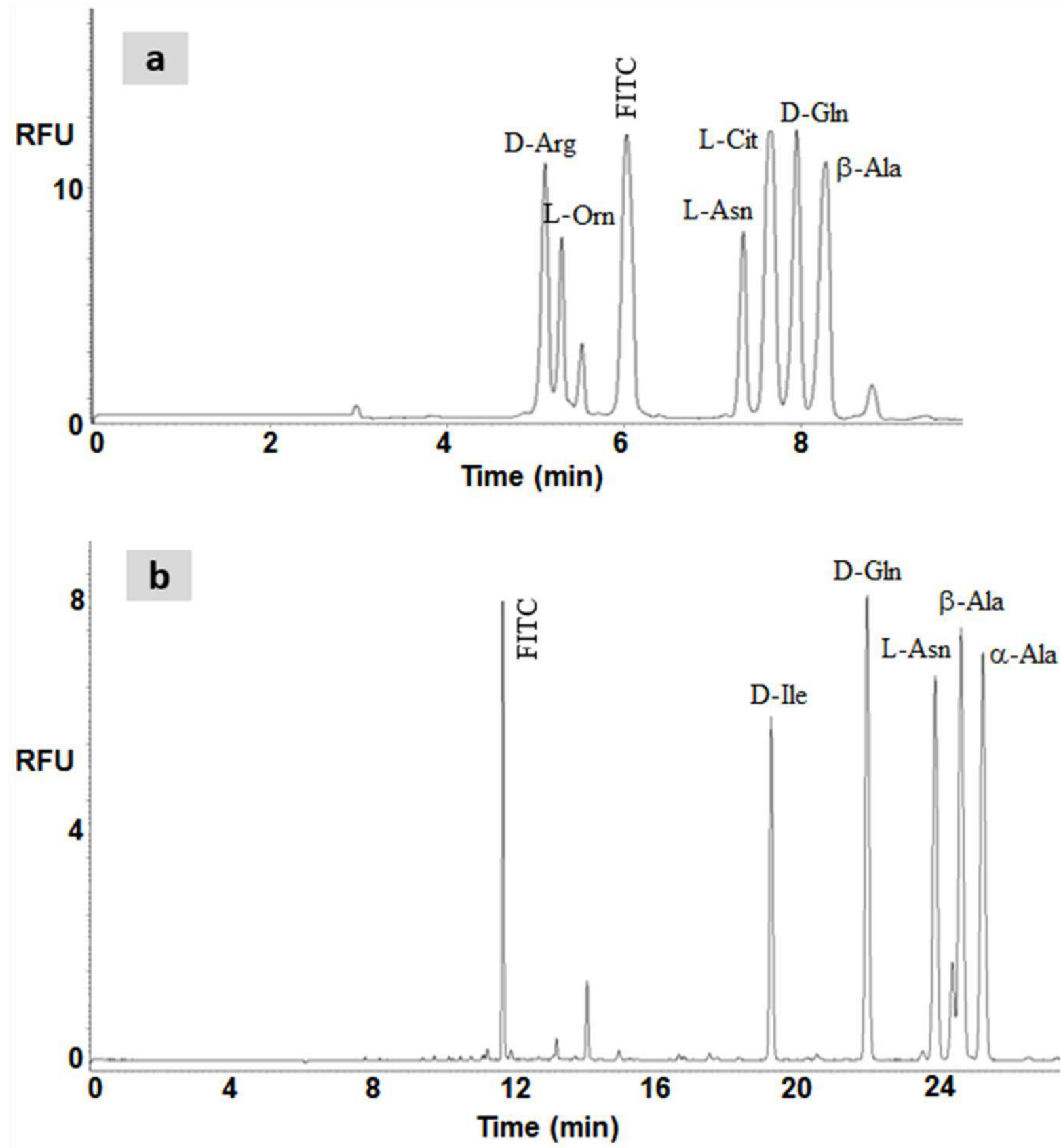
Figure 3. Effect of voltage and extraction time on the concentration of amino acids extracted from Dunaliella salina microalgae by electroporation.

Extraction conditions: $50 \mathrm{mg}$ microalgae suspended in $20 \mathrm{~mL}$ water. Other conditions: see Figure 2.b.
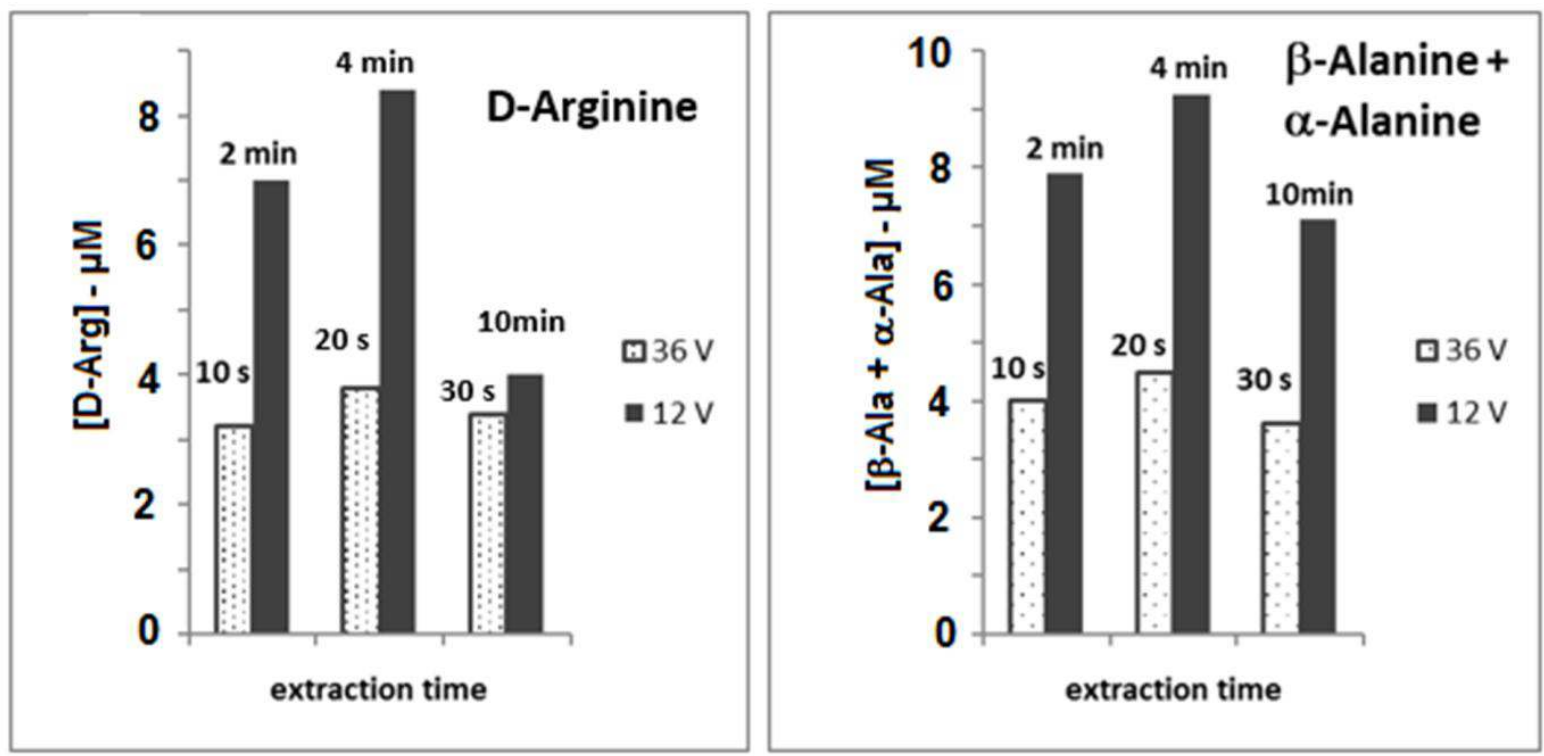
Figure 4. Amino acids identified in Dunaliella salina microalgae sample extracted by electroporation.

Other conditions: see Figure 3.

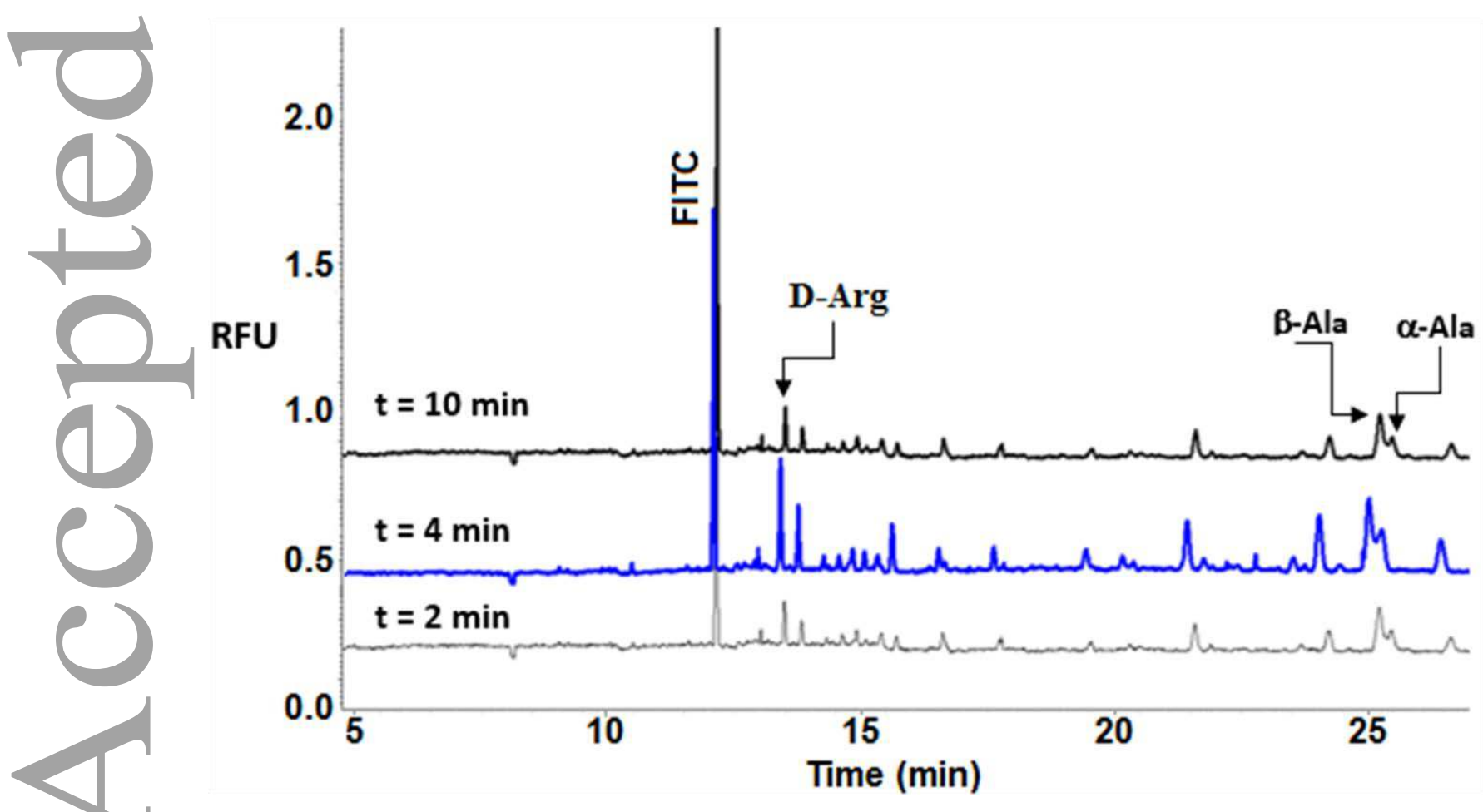


Figure 5. Effect of microalgae cultivation conditions (normal and stressed) on the amount of total extracted amino acids.

Extraction conditions : $12 \mathrm{~V} \mathrm{DC} \mathrm{x} 4$ min. Other conditions: see figures 2 and 3 and section 2.3 .

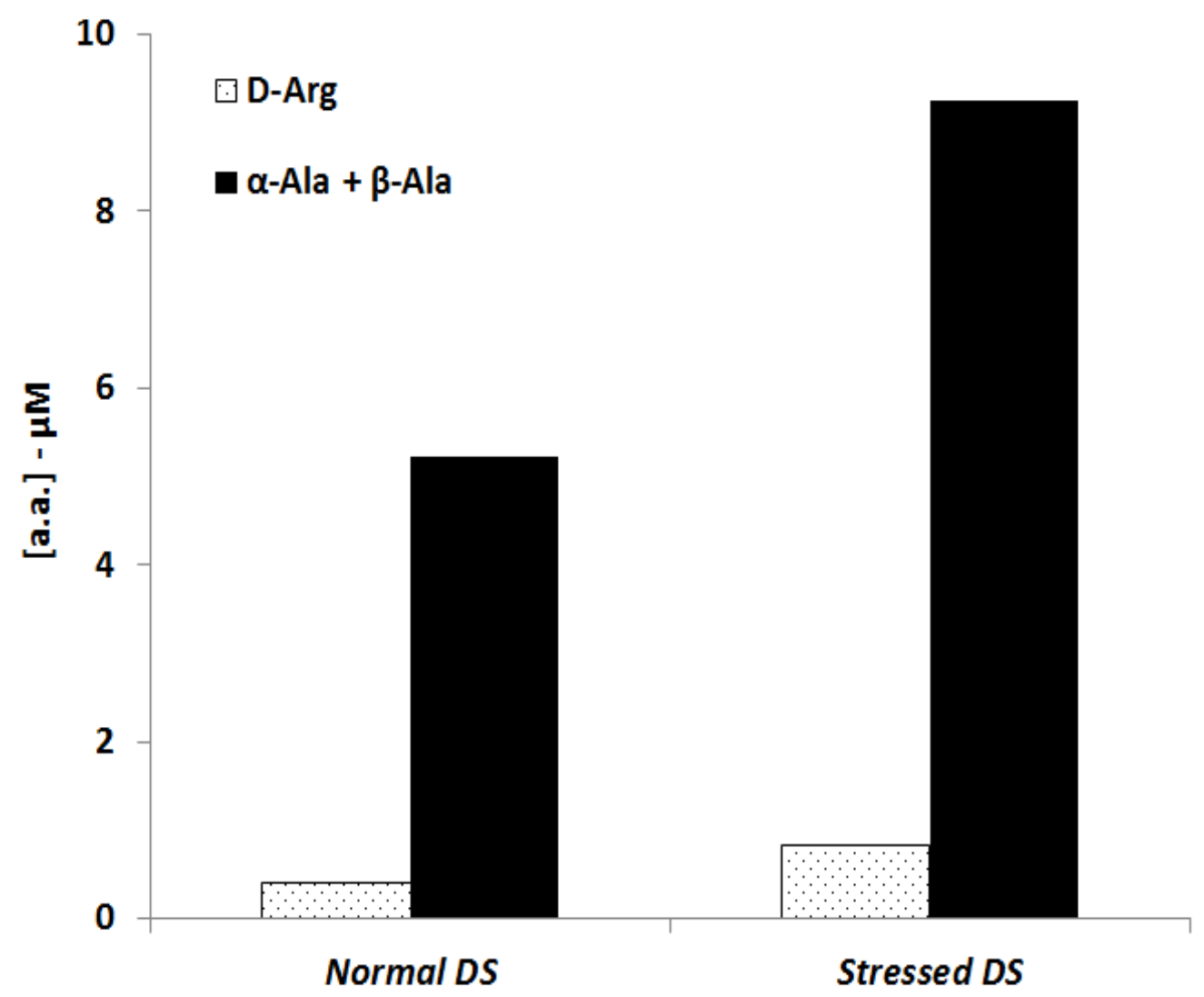


Table 21 . Electrochemical treatment (voltage and extraction time) tested for the extraction of amino acids from Dunaliella Salina microalgae.

\begin{tabular}{clc} 
Voltage $(\mathrm{V})$ & Extraction time & Amino acids identified \\
\hline 6 & $2,4,6,10 \mathrm{~min}$ & No extraction \\
12 & $2,4,6,10 \mathrm{~min}$ & D-Arg, $\alpha$-Ala, $\beta$-Ala \\
36 & $10,20,30,40,50 \mathrm{~s}$ & D-Arg, $\alpha$-Ala, $\beta$-Ala \\
12 (alternative voltage) & $2,4,6,10 \mathrm{~min}$ & No extraction
\end{tabular}

